\title{
Filipinas en la temprana historiografía indiana
}

\author{
por \\ Jorge Mojarro ${ }^{1}$ \\ Universidad de Santo Tomás, Manila, Filipinas
}

Las primeras referencias a Filipinas y al Sudeste Asiático en la historiografía indiana han ocupado tradicionalmente un lugar marginal. Pedro Mártir de Anglería, López de Gómara y Fernández de Oviedo proponen en sus crónicas generales una visión oficial, tanto de la primera circunnavegación del globo como de la presencia española en Filipinas y las Islas Molucas. Este trabajo analiza cómo estos autores se aproximaron a hechos históricos cruciales en los que no estuvieron presentes, con el objetivo de dilucidar cuáles fueron sus estrategias narrativas, su actitud frente a las autoridades clásicas y sus diferencias con respecto a los testimonios directos de los eventos que se narran.

Palabras ClaVE: Filipinas; Islas Molucas; historiografía del siglo XVI; crónicas de indias; literatura colonial.

Cómo CITAR este ARTículo / Citation: Mojarro, Jorge, "Filipinas en la temprana historiografía indiana", Revista de Indias, LXXIX/277 (Madrid, 2019): 631-657. https://doi. $\operatorname{org} / 10.3989 /$ revindias.2019.018.

El proceso histórico de descubrimiento y conquista de nuevas tierras, tanto en el Nuevo Mundo como en el Sudeste Asiático, propició una oportunidad irrepetible para exaltar la grandeza, el heroísmo e incluso la predestinación divina de las naciones europeas - Portugal y España - que tomaron parte ${ }^{2}$. Breves cartas de relación, o relaciones de suceso, empezaron a circular ampliamente en Europa desde muy pronto dando a conocer las primeras noticias

\footnotetext{
1 mojarro@gmail.com, ORCID iD: https://orcid.org/0000-0002-1949-8289.

2 Acerca del mesianismo como deseo y justificación de la empresa conquistadora, véase la excelente monografía de Soler, 2015. Inglaterra y Holanda se sumaron a esta producción de relatos de hazañas en la segunda mitad del siglo XVI.
} de uso y distribución Creative Commons Reconocimiento 4.0 Internacional (CC BY 4.0). 
de una empresa bélica y dominadora, impulsada por el mercantilismo de sus financiadores, que pronto se tiñó de empresa evangélica salvífica y, secundariamente, en un intento simultáneo de conocer la naturaleza, las riquezas y las poblaciones humanas de territorios incógnitos o poco conocidos. Brennan lo sintetiza con nitidez cuando afirma que en la primera mitad del siglo XVI:

... se desarrolló una nueva forma literaria, llamada comúnmente «Historia de Indias», en las que los cronistas produjeron - desde nuestra perspectiva - una extraña y ecléctica mezcla de narración cronológica, descripciones de paisajes, justificaciones de las acciones militares, interpretaciones políticas y curiosidad antropológica acerca de las costumbres, creencias y prácticas sociales de la población nativa ${ }^{3}$.

Las coronas de España y Portugal crearon a propósito la figura del cronista de Indias, un historiador pagado a sueldo por el monarca que atendiera a todos los manuscritos e informaciones referentes a la conquista de América y ofreciera a la posteridad una versión oficial, ordenada y conveniente para defender los intereses reales de la conquista y dominación de los nuevos territorios, así como la magnanimidad de la corona ${ }^{4}$. Sin embargo, no fue infrecuente la libre iniciativa de letrados o intelectuales para tomar la pluma y relatar los hechos con el objetivo de presentar una visión alternativa a la oficial - Bartolomé de las Casas - o la narración de eventos más localizados, como en el caso de las historias de Cieza de León o el Inca Garcilaso. Tampoco escasearon entre los cronistas disputas acerca de la autenticidad y la legitimidad de los relatos que proponían — son conocidos los casos de Fernández de Oviedo, Las Casas, Bernal Díaz del Castillo y Gómara-, con acusaciones más o menos veladas 5 ; igualmente, la ingente tarea realizada no garantizaba ni mucho menos que la obra ganara el derecho a imprimirse, como les ocurrió a Fernández de Oviedo o a Gómara, bien porque la versión que se ofrecía contuviera supuestamente inexactitudes, porque se ensalzara a determinados personajes en detrimento de otros o porque se relataran determinados sucesos que no fueran del interés real que se hicieran públicos ${ }^{6}$.

Las crónicas de Indias son, durante la mayor parte del siglo XVI un subgénero in statu nascendi ${ }^{7}$ derivado de las crónicas medievales, pero con la

3 Brennan, 1996-1997: 227. La traducción es mía.

4 En sentido estricto, la figura oficial del cronista de Indias no fue sancionada legalmente hasta octubre de 1571. Véase Cuesta Domingo, 2007.

5 Adorno, 1992.

6 Serna, 2011.

7 Kohut, 2009: 154. 
peculiaridad de que sus autores mostraban clara preferencia por los modelos historiográficos de la antigüedad - Tito Livio, Plinio el Viejo, Salustio, Tucídides - y no pocas veces su superioridad con respecto al modelo clásico - la emulatio renacentista-: el Nuevo Mundo confirmaba y legitimaba algunas de las fábulas transmitidas por el Viejo Mundo, pero simultáneamente demostraba así la superioridad de estas nuevas tierras y la grandeza creadora del Dios cristiano, mientras sus autores refutaban falsas aserciones de los modelos clásicos, erigiéndose así por encima de ellos en autoridad. Los cronistas de Indias se enfrentaban por primera vez con una ardua dificultad: la de hablar de realidades inéditas y relatarlas en términos comprensibles para una audiencia europea ${ }^{8}$. Esta dificultad comunicativa explica que exista en todos estos textos una tensión expresiva que se hace especialmente evidente a la hora de nombrar y describir paisajes, plantas o animales, buscando insistentemente correlatos conocidos, o tratando de hacer entender al lector, a veces con largas digresiones justificativas, costumbres que estaban fuera de lo humanamente posible según los patrones culturales de conducta de los lectores europeos de la época. «América, además de ser un problema geográfico insalvable, era un problema mental, es decir, un conflicto para la ordenación del mundo establecida por la mentalidad occidental» ${ }^{9}$ : tanto el descubrimiento de América como la circunnavegación del planeta supusieron un impacto de carácter epistemológico que «obligó al pensamiento europeo a crear una forma totalmente innovadora de concebir el espacio global ${ }^{10}$. Traducir ese escollo, explicar un mundo que quedaba redimensionado y hacerlo inteligible constituyeron las tareas que debieron llevar a cabo los cronistas indianos a través de la renovación del género historiográfico y la actualización de los modos y técnicas de narración histórica. Pero no sólo se trataba de hablar del Nuevo Mundo: había que legitimar la conquista mediante un discurso didáctico y moral que proveyera su justificación y necesidad. En un período en el que los límites entre historia y literatura no se habían fijado, los cronistas, buenos conocedores de la importante relación entre la práctica de la historiografía y la retórica, eran autores extremamente conscientes de las convenciones discursivas propias del humanismo - haciéndolas, a veces, explícitas en el texto-y de la labor que estaban llevando a cabo. Es esta naturaleza proteica y maleable del género historiográfico la que habilita su inclusión en el corpus literario de la literatura colonial: la estructura, el estilo narrativo, la selección del material, la perspectiva autoral o la adhesión a una forma más o menos plausible o acep-

\footnotetext{
8 Mora, 1999: 287.

9 Soler, 2015: 201.

10 Ibidem: 225.
} 
tada de verosimilitud son cuestiones de orden literario que asaltan al lector de estas voluminosas obras. De ahí que se afirme que «las narraciones históricas son ficciones verbales que tienen que ver más con sus homólogos en la literatura que con las ciencias» ${ }^{11}$. Estas historias oficiales de los hechos ocurridos en Indias, todas escritas con el objetivo de ser la historia verdadera ${ }^{12}$ y definitiva, imponen, en palabras de Hayden White, un discurso histórico que «narrativiza», es decir, que «finge hacer hablar al propio mundo y hablar como relato» ${ }^{13}$, y que lo diferencia totalmente de las crónicas medievales, en los que la historia era reducida a una mera enumeración de hechos inconexos y sin resolver. En las crónicas de Indias existe un interés por el tratamiento juicioso de las pruebas, los sucesos están dotados de orden, estructura y significación, existe un autor históricamente consciente y subyace una intención moralizante que da sentido al conjunto: «la moralidad como medio de dotar a la realidad de una significación $»^{14}$. Es precisamente esta narratividad, este componente literario del texto, según White, el que le otorga valor histórico. Así pues, el análisis de la historiografía indiana queda incompleto si se reduce a realizar una valoración de la validez o la fiabilidad del texto como fuente histórica ${ }^{15}$, aunque este aspecto llegue a ser en algunas ocasiones muy significativo, de modo que la atención a la forma, la comparación con los modelos literarios, la elaboración del material, la inclusión de digresiones del narrador y el análisis de su particular visión de los eventos - lo que White denomina «moralidad»- son particularmente relevantes para llegar a interpretar cabalmente estas crónicas.

Dentro de la historiografía indiana del siglo XVI, la presencia de Filipinas y del sudeste asiático es ciertamente marginal, a pesar del impacto que produjo en Europa la llegada a Sevilla de la nao Victoria en septiembre de 1522 y de la amplia difusión que tuvieron la relación de Maximiliano Transilvano, el relato de Pigafetta y la rica compilación de testimonios de Giovanni Ramusio. Este déficit informativo en las historias oficiales, más centradas en los acontecimientos que estaban tomando lugar en América, no fue debidamente satisfecho hasta la aparición de la monumental Historia general de los hechos de los castellanos en las Islas y Tierra Firme del mar Océano que

\footnotetext{
11 Mora, 1999: 286.

12 No son pocos los títulos contemporáneos acompañados de este adjetivo.

13 White, 1992: 19.

14 Estas características son extensibles a las historias renacentistas, en las cuales las crónicas indianas deben incluirse. Véase Ibidem: 17-35.

15 Es ésta la injusta acusación que las editoras hacen recaer sobre el fabuloso relato de la expedición de Lope de Aguirre escrito por fray Toribio de Ortiguera. Véase Mampel González y Escandell Tur, 1981: 31.
} 
llaman Indias Occidentales (1601-1615) de Antonio de Herrera y Tordesillas (1549-1626) y de la Conquista de las Islas Molucas (1609), de Bartolomé Leonardo de Argensola (1562-1631) ${ }^{16}$. Hasta entonces, las historias generales que habían hecho propiamente referencia a Filipinas habían sido tan sólo tres: las Décadas del Nuevo Mundo de Pedro Mártir de Anglería (1457-1526), cuya primera edición completa vio la luz en 1530, la Historia de las Indias y Conquista de México (1552), de Francisco López de Gómara (1511-1564?), y la Historia general y natural de las Indias, tierra firme y mar océano (1557) de Gonzalo Fernández de Oviedo (1478-1557), a la que dedicaremos especial atención por ser la obra que con mayor exhaustividad trata de las primeras navegaciones transpacíficas ${ }^{17}$. Dadas las fechas en las que estas obras fueron publicadas, no dan cuenta de la conquista de Filipinas, puesto que ésta no tuvo lugar hasta 1565 , sino que restringen su ámbito a las expediciones de Magallanes-Elcano y Loaysa y a sus respectivas experiencias en Filipinas y las islas Molucas. Esto no significa que no hubiera habido interés por historiar los inicios de la ocupación española de Filipinas a lo largo del siglo; de hecho, no fueron pocos los testigos que tomaron la pluma para legar a la posteridad su particular versión de los acontecimientos, pero el destino no fue generoso con ellos: bien el manuscrito se perdió, como la Historia de Philippinas, en verso, del capitán Andrés Lariz Durango ${ }^{18}$; bien la obra quedó manuscrita, como la Crónica de la Provincia de San Gregorio de Philipinas..., (terminada hacia 1624, pero comenzada hacia 1580) del franciscano Antonio de la Llave19; bien la obra se publicó ya en el siglo $\mathrm{XVII}^{20}$ — casos de la Relación de las Islas Filipinas (1604) del jesuita Pedro Chirino (1557-1635) ${ }^{21}$ o Sucesos de las Islas Filipinas (1609), de Antonio de Morga (1559-1636) - ; o bien el manuscrito fue editado tardíamente, como ocurrió con la poco conocida Historia General de las Islas Occidentales a

16 Esta meritoria crónica barroca, de la que existen traducciones al inglés (1708) y al alemán (1710), aún no ha recibido una edición crítica. Véase Argensola, 2009.

17 Excluimos de esta breve nómina la Geografía y descripción universal de las Indias (1574) de López de Velasco pues, aunque anota la llegada de Legazpi y el asentamiento inicial de los españoles en Filipinas, lo que encontramos es más bien una temprana nota enciclopédica, ausente de narraciones o digresiones.

${ }_{18}$ La cita León Pinelo en su Epitome de la Biblioteca oriental i occidental, nautica $i$ geografica (Madrid, 1629).

19 Se conserva en el Archivo Franciscano Ibero-Oriental de Madrid. Existe copia mecanografiada.

${ }_{20}$ Recordemos que la imprenta de tipos móviles no empezó a funcionar en Manila hasta 1604.

${ }^{21}$ La obra, empero, continuó sumando adiciones y su versión final quedó manuscrita. Finalmente se editó en Chirino, 2000. 
la Asia adyacentes, llamadas Philipinas (1626?), del misionero recoleto Rodrigo de Aganduru Móriz (¿?-1626?)22.

\section{La aVentura magallánica según Pedro Mártir de Anglería}

Un espíritu tan marcadamente renacentista como el de Pedro Mártir de Anglería (1456-1526), italiano exiliado en España ${ }^{23}$, orgulloso de su condición de letrado y armado con su curiosidad humanista, no debió plantearse escribir la primera crónica del descubrimiento del Nuevo Mundo en una lengua que no fuera el latín. La lengua elegida era una declaración implícita de la clase social para la que el milanés escribía: los intelectuales, los altos funcionarios y el prelado, pero esta condición atípica dentro de la historiografía indiana ha determinado ciertamente su poca fortuna crítica en comparación con otros historiadores a pesar de sus indudables méritos ${ }^{24}$. Sus dos mayores obras, la crónica De Orbe Novo (Alcalá, 1530) ${ }^{25}$, dividida en ocho décadas siguiendo el modelo de Tito Livio, y el ingente Opus Epistolarum (Alcalá, 1530), en el que su modelo es Julio César, están íntimamente relacionadas, hasta el punto de que su historia es fruto de su ingente intercambio epistolar.

La carta referente a la expedición liderada por Magallanes, titulada De Orbe Ambito, fue enviada originalmente al papa Adriano VI (1459-1523), quien pretendía editarla lujosamente. Esta referencia nos indica que se debió redactar a lo largo de 1522 o principios de 1523, recabando información entre los miembros de la expedición. El destinatario de la carta murió antes de recibirla y el documento se perdió durante el saco de Roma (1527). Pedro Mártir debió haber realizado copia de la carta, pues la incluyó como capítulo

22 Fue finalmente rescatada en la Colección de Documentos Inéditos para la Historia de España, Madrid, Imprenta de Miguel Ginesta, 1882, vols. 78 y 79.

23 Sus avatares biográficos están muy bien resumidos en la "Introducción" de Ramón Alba a Mártir de Anglería, 1990: VII-XIX. Las citas se referirán siempre a esta edición. Véanse también Riber Campins, 1964 y Salas, 1960: 15-60.

24 A este hecho habría que sumarle que la primera traducción al español no vio la luz hasta 1892. Debemos matizar que el interés de los estudiosos por su obra ha aumentado considerablemente en los últimos veinte años, pero aún no existe un estudio de conjunto acerca de su producción.

${ }_{25}$ La primera muestra de su trabajo fue el raro Libretto de tutta la nauigatione de re de Spagna de le isole et terreni nouamente trouati (Venecia, 1504), que es síntesis de la primera década latina. Contiene información acerca de los primeros tres viajes de Colón y fue plagiada en la compilación Nuovi Paesi Ritrovati (Vicenza, 1507) y adjudicada a Vespuccio. Véase Cro: 2003. Una erudita investigación acerca de las sucesivas ediciones de las Décadas de Pedro Mártir y sus traducciones se halla en el citado artículo de Brennan, 1996-1997. 
séptimo de la quinta década, manteniendo tanto el título como la dedicatoria originales ${ }^{26}$.

Si hacemos caso omiso de las escasas ocasiones en que el autor se dirige al sumo pontífice, la carta se lee como un relato de amena lectura en el que sobresalen varios rasgos: como es de esperar en un intelectual de su talla, despliega elocuencia, hace uso de un estilo artificioso y florido, y muestra — sin abusar de ella - una cierta predilección por la frase larga, notas características de su modo de escribir, lo que le traerá críticas $^{27}$; la cita clásica o la comparación con hechos de la antigüedad eran recursos que le servían para cumplir con una doble función: hacer alarde de erudición y elogiar las hazañas de los héroes castellanos. Así, los recovecos del estrecho que dan paso al océano Pacífico se comparan a «dos gargantas estrechas que abarcan cierto espacio ancho en el Helesponto» ${ }^{28}$, Malaca es llamada Quersoneso Áureo mientras que las Islas de Cabo Verde son denominadas las Gorgonas $^{29}$, y los supervivientes de la expedición superan en grandeza a los argonautas griegos, elogio que coincide en términos con el que les dedicó Maximiliano Transilvano:

Si esto lo hubiese realizado un griego, ¡qué no habría inventado la Grecia acerca de esta novedad increíble! Dígase qué es lo que hizo la nave de los argonautas, la cual, sin avergonzarse ni reírse, cuentan supersticiosamente que fue llevada al cielo. Si reflexionáramos lo que hizo esa nave, saliendo de Argos al Ponto llegó a Oetes y Medea con sus héroes Hércules, Teseo, Jasón: no sé lo que hizo; la gente no sabe aún qué fue el vellocino de oro, y el trecho de camino que hay de Grecia al Ponto lo han aprendido los muchachos de las gramatiquillas: la uña de un gigante es mucho mayor que esa distancia ${ }^{30}$.

Consciente de que no era testigo de los acontecimientos que se narraban y de que esta distancia iba en detrimento de su credibilidad, Pedro Mártir lleva a cabo un trabajo de criba de fuentes que a veces se revela al lector. Respecto a las conspiraciones que existieron para amotinarse contra Magalla-

26 Se trata del único capítulo de la obra con título, pues iban numerados indiferentemente. La década quinta estaba dedicada al papa Clemente VII (1478-1534), su sucesor.

27 López de Gómara, 1979: 71, dirá del cronista italiano que «escribió muchas cosas de las Indias en latín, pues era cronista de los Reyes Católicos; algunos quisieran más que las escribiera en romance, o mejor y más claro».

28 Mártir de Anglería, 1990: 354.

29 Ibidem: 361.

30 Ibidem: 360. En otros capítulos de las Décadas, este apego a los mitos clásicos repercutirá en la difusión de leyendas como la de las amazonas. Véase al respecto, Coello de la Rosa, 2012: 118-120. 
nes, arguye que «este asunto y otros a éste semejante, lo cuentan varios de varias maneras $»^{31}$, un intento - poco convincente, como veremos - de mostrar objetividad y rigor; en otras ocasiones, hace uso de una experiencia diferida, como cuando habla del pan de palma de los nativos de unas islas indeterminadas: «quise yo probarlo, no hay cosa más áspera y más insípida; debe ser el alimento de los pobres necesitados, que no alcanzan arroz por no tener tierra de cultivo» ${ }^{32}$; con respecto a las muestras de ramas de clavo que trajo la nave Victoria, afirma:

Yo obtuve la mayor parte de las ramas traídas: repartí a varias personas muchas para enviarlas a diversas partes: aún me quedan unas poquitas, que las reservaré hasta que sepa si ha llegado alguna de ellas a manos de Vuestra Santidad ${ }^{33}$.

Mártir es un cronista extremadamente precavido en lo que se refiere a la inclusión en su carta de elementos fantásticos e inverosímiles. Es el único cronista de la primera circunnavegación que omite el dato de la gigantez de los patagones; así mismo, elide toda referencia a la tribu que se cubría al dormir con sus propias orejas, no menciona el ave sagrada de los habitantes de la Molucas - de la cual se habían llevado ejemplares a la corte-; no hace referencia al canibalismo de las islas limítrofes ni habla, como Pigafetta, de las hojas que caminan al caer al suelo. Apenas concede una mención a un pez monstruoso, sin escamas, con dos cuernos de hueso y «cara de puerco» ${ }^{34}$.

El cronista milanés se detiene en detallar prolijamente en la enumeración de los vegetales comestibles o los variados usos del coco en Filipinas, y en estimar, con bastante inexactitud en grados, la localización geográfica de las nuevas tierras. Los elementos propiamente narrativos se despachan en pocas frases, de manera sintética, refundida por sus frecuentes digresiones: Mártir sostiene, basándose en un superviviente, que la causa de la traición de los cebuanos fueron los celos por sus mujeres, idea que sugiere en otros términos Pigafetta en su relación; también opina que las especias son banalidades que «afeminan a los hombres» ${ }^{35}$, mientras que para Magallanes no guarda palabras de elogio: le acusa de ensañarse con Juan de Cartagena, uno de los amotinados durante el paso del estrecho, mientras que al morir en la refriega de Mactán, su comentario delata una falta total de empatía: «De este modo el

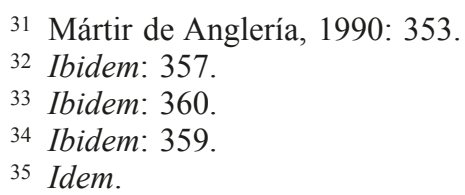


buen portugués Magallanes concluyó con su codicia de aromas» ${ }^{36}$. Mártir trata de dar una explicación a que los españoles supervivientes pensaran que se hallaban al volver a España en un día anterior, algo hizo Pigafetta al final de su narración con muchas menos palabras. Quizás la digresión más interesante sea aquella en la que se queja de los puristas del latín por no permitirle acuñar términos nuevos para denominar realidades nuevas:

Si a uno de esos que no cuidan de acumular para su alma otros tesoros que el ser latinos, por más que la lengua latina no tenga tal palabra y se pueda tomar muy bien de otra, se le pregunta si en latín es permitido decir «anapelo», se pondrá a refunfuñar, y dando un resoplido con solemne gravedad murmujeará que aquella cosa debe llamarse «estrangulador del lobo». Conque así, a mi ver, con permiso de esos sabihondos, las islas Molucas abundan en naranjas, limas, limones, toronjas, cidras, cidrones, ranadas, manzanas y hortalizas ${ }^{37}$.

La elección del latín no permitía al cronista milanés la libertad de expresión de que gozaban aquellos que se decantaban por las lenguas vernáculas. Sus Décadas acuñan por primera vez palabras que tendrán un tremendo éxito, como «colonia» o «Antillas», pero los neologismos no estarán a su alcance, y de ahí su ingenioso desahogo. Una comparación de este capítulo VII, exclusivamente dedicado a la circunnavegación, con otras fuentes primarias, delata, por encima de todo, su tremenda precariedad. Tras un manto de curiosas digresiones, virtuosismos estilísticos, referencias clásicas y alguna que otra redundancia se nos oculta una escasez de informaciones y algún que otro error contundente: hasta en dos ocasiones se da a entender al lector que la navegación pasó por Borneo antes que por Cebú, mientras que el robo perpetrado por los navegantes al junco que iba cargado de mercancías no ocurrió en las inmediaciones de las Molucas, sino en Borneo. La pírrica sustancia de su relato se hace más evidente cuando se trae a colación De Moluccis Insulis, un texto de similar impronta humanista pero que ofrece al lector una información más consistente y organizada. La presencia española en Cebú se reduce a la batalla de Mactán y a la traición final, mientras que de los habitantes de las islas de las Especias apenas menciona al rey. Esta escasez informativa es si cabe aún más llamativa si tenemos en cuenta que se debió redactar poco después de entrevistarse con los supervivientes, que otros capítulos de sus Déca-

36 Ibidem: 355. Que Pedro Mártir no sentía ningún aprecio por los portugueses es algo que se deduce fácilmente de la lectura de las Décadas. En esta misma carta hace una defensa acérrima de la propiedad española de las Molucas e incluso de Malaca por caer, según él, dentro de la demarcación acordada.

37 Ibidem: 358. 
das referentes al Nuevo Mundo están repletos de datos acerca de los nuevos pueblos y sus costumbres, y de que, por encima de todo, era un evento histórico que merecía una redacción más cuidadosa. Mártir no quiso valerse del De Moluccis Insulis como fuente de su De Orbe Ambito, quizás en un intento vano por superar en calidad al impreso del joven humanista bohemio. En cualquier caso, el texto demuestra su naturaleza transicional e híbrida: un recuento deshilvanado y sintético que trataba de deshacerse, sin fortuna, de viejas formas de historiar, mucho más afortunada a la hora de relatar otros eventos. Esta interesante y pionera historia de los descubrimientos recientes, escrita a distancia, aunque contemporáneamente, tenía como motivo central de su obra la novedad: una compilación de origen epistolar que, en orden cronológico, trataba de informar a Europa con inmediatez de los trascendentes acontecimientos ultramarinos. En lo que se refiere al pequeño fragmento que nos ocupa, había dos noticias que destacar: que las islas Molucas eran españolas y que la nao Victoria había logrado dar la vuelta al mundo. Sin embargo, las lagunas informativas señaladas sólo salen a la luz cuando se comparan otras fuentes del acontecimiento. Anglería emprendió su tarea historiográfica «menos como una disciplina científica que como una de las más bellas artes, sometida a las leyes de la poética y no a las del rigor empírico» ${ }^{38}$.

\section{El eXCUrso asiático en la Historia GeNERAL de LAS INDIAS (1552)}

La obra de Francisco López de Gómara (1511-1559) se reduce principalmente $^{39}$ a Hispania Victrix, dividida en dos partes: Historia General de las Indias y Conquista de México ${ }^{40}$, de la que los comentaristas han resaltado su visión imperialista y propagandística de la conquista ${ }^{41}$, la conciencia de su labor de historiador como creador de un discurso legitimador y establecedor ${ }^{42}$, su amplia formación intelectual, su erudición humanista y algunos rasgos medievales en su quehacer historiográfico ${ }^{43}$. Su estilo breve, llano y conciso,

\footnotetext{
38 Ruíz Pérez, 1993: 57.

39 También escribió una Historia de los Barbarroja (1545) y una Historia de los hechos de Hernán Cortés (1548-1560) en latín. Quedaron inéditos.

40 Disfrutó de seis ediciones entre 1552, fecha en que vio la luz en Zaragoza la primera parte, y 1554.

41 Este aspecto se estudia muy pormenorizadamente en Roa-de-la-Carrera, 2005.

42 Cazés, 2007.

43 Las características principales de su prosa están muy bien sintetizadas en Valcárcel Martínez, 1989. También se ha señalado que su obra está permeada por un escepticismo moderado. Véase Castany Prado, 2009.
} 
y la selección de los eventos precisos y relevantes, siguiendo las premisas del Juan Luis Vives en su De Tratendis Disciplinis (1555), harán de su historia una obra de amena lectura, una narración de los eventos coherente desde el punto de vista discursivo que, proponiéndose como canónica y digna de ser traducida a otras lenguas europeas, acabó siendo polémica debido a su parcialidad en favor de Hernán Cortés — de quien fue capellán durante seis años-, sus ausencias, su falta de conocimiento de la realidad y su visión edulcorada del proceso de conquista ${ }^{44}$.

Los capítulos de la primera parte que van del XCI al CVII están dedicados a las expediciones transpacíficas a Filipinas y las Molucas. Gómara sintetiza los prolegómenos a la salida de las expediciones de Magallanes; al igual que Pedro Mártir, su opinión acerca del líder portugués es desfavorable: «era creído» ${ }^{45}$; después de detallar su cruenta muerte en la batalla de Mactán, finaliza con cierta ironía: «de esta manera acabó Magallanes su vida y su demanda, sin gozar lo que halló» ${ }^{46}$. La praxis historiográfica de nuestro cronista concentraba su discurso en torno a las hazañas de grandes hombres, pero en el relato de la circunnavegación el liderazgo del portugués $\mathrm{y}$, después, la ausencia de una personalidad descollante, actúan como elementos que dificultan el foco de la narración. Gómara opta por reelaborar los datos y añadir multitud de informaciones nuevas: así, hasta en dos ocasiones se nos menciona a una esclava de Sumatra que sirvió de traductora que no aparece en ninguna otra fuente. Los testimonios de los testigos presenciales nos hablan tan sólo de Enrique de Malaca, instigador de la rebelión en Cebú. Las interacciones con los patagones y el intercambio de presentes derivan, claramente, del relato de Pigafetta, pero Gómara añade datos de su propia cosecha en aras de proporcionar un discurso más cohesionado y verosímil. Esta crónica es la única que menciona que fue precisamente Enrique de Malaca el que predicó el Evangelio, con toda probabilidad como intermediador lingüístico entre el fraile y los nativos. Así mismo, proporciona información adicional acerca de las razones por las que los cebuanos, bautizados en masa y amigos de los españoles, acabaron por tender una emboscada a los desprevenidos españoles, forzándoles a huir:

Entendieron en rescatar por la isla oro, azúcar, jengibre, carne, pan y otras cosas, para irse a las Malucas entre tanto que sanaban los enfermos, y tratando de conquistar a Maután; y como para lo uno y para lo otro era menester Enrique, dábanle prisa a levantar. Él, como sentía mucho la herida de yerba, no podía o no

44 Entre sus críticos más acérrimos destacan Bernal Díaz del Castillo, Fernández de Oviedo y Bartolomé de las Casas.

45 López de Gómara, 1979: 127.

46 Ibidem: 147. 
quería, según algunos pensaban; y reñíanle Serrano y Barbosa, amenazándole con doña Beatriz, su ama ${ }^{47}$. Tanto, en fin, que, o por las injurias o por haber libertad, habló con Hamabar [el rey de Cebú] y consejóle que matase los españoles si quería ser, como hasta allí, rey de Zebut, diciendo que eran codiciosos en demasía y que trataban guerra al rey Cilapulapo con su ayuda, y usurparle después a él su isla; que así hacían doquiera que hallaban entrada y ocasión ${ }^{48}$.

Gómara procede, pues, añadiendo detalles allí donde cree que la información es relevante, y resumiendo o elidiendo deliberadamente todo aquello que no redunda en la misión didáctica y propagandista de la narración. Se trata de un proceso de ficcionalización muy interesante y que cabría reconstruir, dato a dato y comparativamente, atendiendo a los testimonios de los testigos supervivientes. Sin embargo, lo más relevante es que el resultado de su crónica, a fuerza de suplir la realidad de unos eventos dispersos y localizados en una geografía más bien indeterminada, y de acomodarlos a un ritmo narrativo consistente, acaba por serle al desavisado lector tan convincente y verosímil como el relato de Pigafetta. Desde el punto de vista literario, ahí reside su gran mérito.

La elisión y la síntesis son las otras estrategias narrativas a las que recurre Gómara para dotar a la Historia de cierta densidad informativa. Sabemos a través de Pigafetta que llegaron a Cebú guiados por el reyezuelo de Butuán, tras haber pasado por Homonhon y poco después de su breve estancia en las Islas de los Ladrones. El capellán de Cortés despacha ese intervalo crucial con un «llegaron en conclusión, de isla en isla, a Zebut» ${ }^{49}$; las expediciones lideradas por Loaysa y Saavedra Cerón apenas le merecen una breve mención, probablemente porque eran empresas fracasadas en las que no creyó oportuno hacer énfasis. Para Gómara sólo era historiable aquello que era de sustancia y redundaba en el buen nombre de los españoles ${ }^{50}$.

De los nativos de Cebú no se ofrece una imagen nítida, sino una caricatura a base de retazos: apenas unos seres pasivos, de fácil evangelización, traicioneros y de costumbres risibles. Según Gómara, el mismo rey «bebía de las porcelanas con una caña, cosa de risa para los nuestros» ${ }^{51}$. Aunque demuestra curiosidad por las formas de organización social y referencia todo aquello que

47 Beatriz era la esposa de Magallanes. Esta mención no aparece en ninguna fuente, pero es muy creíble. A la muerte del dueño, el esclavo quedaba automáticamente liberado. Este conflicto debió contrariar a Enrique y moverlo a buscar su libertad apoyando a los cebuanos.

48 López de Gómara, 1979: 143.

49 Ibidem: 141.

50 Valcárcel Martínez, 1989: 15.

51 López de Gómara, 1979: 143. Esta actitud irónica y altanera con respecto a la otredad indígena ha sido señalada por varios estudiosos, entre ellos, Valcárcel Martínez, 1989: 14 y Castany Prado, 2009: 17. 
es nuevo para el lector, sus juicios denotan una dualidad jerárquica, donde las culturas nativas rara vez son tildadas en términos positivos. Así, la creencia indígena, en las Molucas, de que no existe nada más allá de la vida y la muerte le parece «bestialidad grandísima» 52 , y recalca que «todos aquellos isleños son celosos, teniendo muchísimas mujeres $\rangle^{53}$. Las costumbres vienen enumeradas de un modo bastante escueto, con pocas digresiones, como en un resumen apresurado. Igual tratamiento, reciben los productos de las islas. Como en todos los testimonios contemporáneos, la Historia menciona el oro, el azúcar y el jengibre de Cebú, así como la variedad de usos del coco ${ }^{54}$. En las Molucas, los españoles se interesan principalmente por saber cómo negociar la compra de especias y conocer los árboles que las producen: en su narración, no son sólo valientes, sino que no pierden el tiempo y se emplean con diligencia en la consecución de la difícil misión encomendada.

Uno de los aspectos menos modernos de esta crónica, para el lector de hoy, quizás sea la falta de referencias, fuentes y testigos con respecto al reguero constantes de informaciones aportadas, así como la inclusión de elementos de orden fantástico: Gómara habla, como Pigafetta, de «unos árboles cuyas hojas en cayendo andan como gusanos» o de la existencia de enormes «perlas como huevos de gallina» 55 ; repite, como el italiano, que los habitantes de Borneo «no hurtan ni matan» ${ }^{56}$; también menciona el caso del «pez con hocico de puerco» ${ }^{57}$ al que ya había hecho referencia Pedro Mártir. Nuestro cronista, como compilador y ensamblador de testimonios, no cuestiona su veracidad: la historia debía ser didáctica y amena, y las extrañezas ultramarinas añadían indudablemente interés a su relato. Su conciencia de autor, de hombre que legaba a la humanidad el relato de las grandes hazañas de su país, redundaba en el ocultamiento de sus fuentes y en el proponerse, implícitamente, como referencia primera de los hechos, actitud que le criticarán agriamente Las Casas, Fernández de Oviedo y Bernal Díaz del Castillo. La única ocasión en que trata de contrastar las fuentes, sin mencionarlas, es en el caso del recibimiento del rey de Tidore, quien dijo a los españoles que ya sabía de

52 López de Gómara, 1979: 146.

53 Ibidem: 148.

54 La infinidad de usos de este producto, como comida, como fuente de agua, para hacer licores y vinagre, para hacer ropa con la cáscara, etc., es mencionada sistemáticamente por casi todos los tempranos cronistas de Filipinas y podría ser un buen punto de partida para esbozar un esquema de la transmisión de los conocimientos. Parece ser que la fuente original de esta larga información es, de nuevo, Pigafetta.

55 López de Gómara, 1979: 146 y 147.

56 Ibidem: 146.

57 Idem. 
su llegada gracias a las estrellas, mientras que otros — se trata de Pigafettahablan de que lo había visto en sueños. Gómara concluye pragmáticamente arguyendo que «fue por conjetura», al saber que los portugueses ya llevaban varios años merodeando por la zona.

El heroísmo de los supervivientes de la nao Victoria y la trascendencia histórica de la hazaña de la circunnavegación constituyen el evento idóneo para ensalzar grandilocuentemente a los españoles en términos de superioridad con respecto a los ídolos de la antigüedad. Pocos fragmentos tan ilustradores y celebradores en las crónicas de Indias como el correspondiente al final del capítulo XCVIII de la Historia de Gómara, que curiosamente coincide en fórmula con la empleada por Maximiliano Transilvano en su impreso latino, pero ampliada con nuevas menciones:

Grande fue la navegación de la flota de Salomón; empero mayor fue la de estas naos del emperador y rey don Carlos. La nave Argos, de Jasón, que pusieron en las estrellas, navegó muy poquito en comparación la nao Vitoria, la cual se debiera guardar en las atarazanas de Sevilla por memoria. Los rodeos, los peligros y trabajos de Ulises fueron nada en respecto de los de Juan Sebastián; y así, él puso en sus armas el mundo por cimera, y por letra Primus Circundedisti Me, que conforma muy bien con lo que navegó, y a la verdad él rodeó todo el mundo ${ }^{58}$.

El cronista soriano ofrece, en lo que se refiere a los avatares de los españoles a través del Pacífico, una historia acabada y muy consistente desde el punto de vista literario: un relato trágico y sinuoso de supervivencia con final feliz. Poco le importaban al autor de esta Historia — siguiendo el modelo de Heródoto - las incoherencias factuales cuando se trataba de legar a la posteridad una versión oficial, ricamente aderezada, que enfatizaba los logros y suprimía los errores. Filipinas y las Molucas vienen a ser aquí el lejano y exótico marco donde enaltecer un capítulo magnífico de las ejemplares aventuras ultramarinas de los españoles.

\section{El Libro XX De la Historia General Y NATURAL DE LaS INDias (1557)}

Gonzalo Fernández de Oviedo (1478-1557) dedicó la segunda mitad de su vida a la realización de una tarea tantálica: la redacción de la Historia General y Natural de las Indias, cuya primera edición vio la luz en $1535^{59}$. Como escritor, se había estrenado con una novela de caballerías, Claribalte (1519), de

\footnotetext{
58 Ibidem: 150.

59 Y reimpresa bajo su supervisión en Salamanca en 1547. Véase Ramos Pérez, 1965.
} 
la que posteriormente renegó, y ya había dado un avance de su quehacer como documentalista del Nuevo Mundo en el Sumario de la Natural Historia de las Indias (1526). Para entonces, en opinión de sus biógrafos ${ }^{60}$, ya había empezado a trabajar en su magna obra, cuya primera parte, en diecinueve libros, vio la luz en Sevilla en $1535^{61}$. La crítica ha señalado la hibridez de su escritura, donde se conjuga lo vivido por el autor con la inserción de datos procedentes de fuentes consideradas fidedignas ${ }^{62}$, donde se mezclan los hechos pasados y los recientes, con un proceso de redacción intricado y, a veces, de resultado desigual en su afán por tener un texto actualizado, exhaustivo y verosímil añadiendo cuantas informaciones fueran llegándole ${ }^{63}$. Oviedo es un cronista enormemente consciente de su tarea y, en las copiosas digresiones con que riega su obra, dejó una serie de reflexiones jugosas acerca de la labor del historiador. Dos rasgos se encuentran explícitos e implícitos en su obra: su voluntad de escribir llanamente, la claridad expresiva, y por otro lado su obsesión por obtener la versión más verdadera de los eventos que estaban ocurriendo en las nuevas tierras: ejerce, consciente de la importancia de la misión del historiador, «un alto sacerdocio de la verdad, que impone una religiosa entrega a la exactitud y a la integridad de la información» ${ }^{64}$. Como cronista, Oviedo se enfrenta a su inmensa tarea de modo sistemático: como historiador, pero también como geógrafo, como naturalista, como etnógrafo y, no pocas veces, como psicólogo, en su intento por comprender las razones que llevaban a los hombres a actuar de una determinada manera y desechando o poniendo en duda a testigos presenciales que le servían de fuentes atendiendo a su carácter y su moral. Esta voluntad de exhaustividad, omniabarcadora ${ }^{65}$, incide en la estructura formal de la obra, cuya principal característica es la heterogeneidad. Coello de la Rosa la define como:

... una obra compuesta por un conjunto de relatos y narraciones legendarias, narraciones episódicas, digresiones anecdóticas, diálogos ficticios, en suma, estilos

60 Fernández de Oviedo no tuvo la vida reposada que requería la empresa que se propuso llevar a cabo. Para todo lo referente a su biografía, sigue siendo muy útil la introducción del último editor moderno de su obra: Pérez de Tudela Bueso, 1959. Véase también, Gerbi, 1992: 151-169 y Myers, 2007: 12-25.

61 Gerbi, 1992: 163, lo considera «un italiano del Cinquecento por su formación mental, por su curiosidad científica, por su elevado concepto del oficio de historiador, y finalmente por el sutil humorismo».

62 En este sentido, se han señalado los modelos de Polibio, Tucídides y Flavio Josefo, como historiadores presenciales de los hechos que se narraban. El modelo contrario era, como hemos señalado, Heródoto, seguido por Gómara.

63 Kohut, 2009: 163-166.

64 Gerbi, 1992: 268.

65 Ibidem: 274. 
de contar las experiencias vividas en el Nuevo Mundo, impregnadas de providencialismo y de otros juicios de valor provenientes de una formación retórica tradicional —Aristóteles, Cicerón, Quintiliano-y de la pastoral judeocristiana ${ }^{66}$.

Las historias de las expediciones de Magallanes y Loaysa constituyen el contenido del Libro XX de la Historia de Oviedo, primer libro de la segunda parte, que vio la luz en Valladolid en 1557. Este Libro XX es el más largo de cuantos constituyen la colección y planteó un problema bibliográfico que ya ha sido resuelto: la primera edición de este libro XX se imprimió por primera vez en Salamanca hacia 1548 como continuación de la reimpresión ampliada de la primera parte, que contenía los primeros diecinueve libros. Oviedo dio por hecho que tenía licencia para imprimir el resto de la obra, pero la intercesión en su contra de Las Casas — que cita Gómara- impidió que se siguiera publicando ${ }^{67}$. De esta primera edición, sin fecha ${ }^{68}$ ni portada, se conserva tan sólo un ejemplar en la Newberry Library, y contiene algunas breves diferencias con respecto a la edición de 1557. La más importante de ellas es una introducción general a la segunda parte, dedicada al rey y redactada en 1544, en la que se elogia el heroísmo de los españoles y se exaltan las conquistas españoles como muy superiores a las logradas por Alejandro Magno ${ }^{69}$. Oviedo enlaza el origen de la monarquía española con la aparición de los godos y se refiere a Túbal como el primer español; recordemos que durante el Renacimiento el pensamiento histórico estaba fuertemente ligado a las concepciones legendarias del pasado ${ }^{70}$. Este origen gótico de España era clave en su teoría providencialista del descubrimiento, según la cual Cristóbal Colón no había descubierto unas tierras pobladas por los descendientes de una antigua diáspora: era Dios quien había guiado a Colón a América para proceder a la evangelización de unos hombres que, por origen, pertenecían legítimamente a España ${ }^{71}$.

66 Coello de la Rosa, 2012: 22.

67 Rey, 1927: 52-57.

68 Turner, 1983, trata de demostrar que el libro se imprimió en 1552 y que la publicación de la parte segunda, con la que formaba una unidad, se interrumpió debido a la falta de fondos. Sin embargo, su datación trata de evidenciarse en una transcripción errónea de una carta.

${ }^{69}$ Fernández de Oviedo y Valdés, 1852, vol. II: 3-4. Nos referiremos siempre a esta edición.

70 Serna, 2009: 161.

71 Coello de la Rosa, 2012: 32-33. Otra diferencia entre las dos ediciones es que la primera contiene algún material adicional en los primeros y últimos folios que, en esencia, no alteran el contenido de la obra. Mientras que la edición de la Newberry Library termina lógicamente dando paso al Libro XXI, que nunca se pudo imprimir, la edición de 1557 elimina un párrafo final e informa de la muerte de su autor. 
Para un autor como Oviedo, tan atento a la concepción moral y didáctica de la empresa historiográfica, la narración de la primera circunnavegación del mundo se presentaba como una oportunidad única para dar a conocer de qué eran capaces unos pocos españoles enfrentados a lo desconocido, superando numerosos peligros y contratiempos, pasando frío y hambre, surcando mares incógnitos por primera vez, al mando de dos hombres que ejemplificaban el caso del héroe clásico por su valor, determinación e integridad moral: Magallanes y Elcano. Su Historia enumera, en el capítulo V que sirve de bisagra para pasar a la expedición de Loaysa, las cinco navegaciones más «señaladas del mundo»: la del arca de Noé, la de Jasón — llamada Argos-, la de Sosi - rey de Egipto- , dedicada al dios Tebas, la de Cristóbal Colón y, finalmente, la nao Victoria, comandada por Juan Sebastián Elcano. Esta corta lista demuestra cómo lo bíblico, lo profético y lo clásico se anudaban a las emulaciones de los hechos contemporáneos de los españoles: la circunnavegación culminaba una serie de eventos dignos de ser recordados por la humanidad. Pero el problema que encontró Oviedo para redactar este capítulo fue que debía traicionar el modus scribendi del cual se había preciado anteriormente: su calidad de testigo ocular de los hechos narrados o su familiaridad con las tierras de las que hablaba. Si hubo algo que Oviedo criticó más encarnizadamente a sus predecesores, fue precisamente que escribían de oídas, sin haber visto nada del Nuevo Mundo, con lo cual sus obras carecían del rigor que debía tener una obra histórica. Para solventar este problema, nuestro cronista se ve obligado a llevar a cabo un escrutinio detallado de las fuentes escritas, se basa en los testimonios de algunos supervivientes de las dos expediciones, y recurre, en los casos más dudosos, a las autoridades de la antigüedad clásica, sobre todo Plinio. Esto tuvo dos consecuencias: la primera de ellas afecta a la estructura del Libro XX. De los treinta y seis capítulos que lo conforman, sólo cuatro corresponden a la expedición de Magallanes, a pesar de su importancia histórica: apenas un tercio del libro. Esto pudiera deberse a que Oviedo escribiera acerca del acontecimiento pasados algunos años, pero lo más llamativo es que renuncia a ofrecer una narración ordenada de los hechos, no ejerce una labor de síntesis: el capítulo primero es en su mayor parte traducción y paráfrasis de la relación de Maximiliano Transilvano; en los capítulos segundo y tercero vuelve a narrar la aventura pero esta vez tomando como base la relación de Pigafetta, cayendo en algunas redundancias; el capítulo cuarto, más corto, es fruto de sus conversaciones con Juan Sebastián Elcano, Hernando de Bustamante ${ }^{72}$ y Gonzalo Gómez de Espinosa, superviviente de

72 Este Hernando de Bustamante también sobrevivió a la atribulada expedición de Loaysa, lo cual le convierte en la primera persona en dar dos veces la vuelta al mundo. Terminó 
la Trinidad. Esta inusual organización tenía como resultado no una narración unitaria de los hechos, sino la simple exposición de las tres fuentes principales: el objetivo era hacer partícipe al lector de la metodología judicial que le servía como el modo más riguroso de exponer unos eventos en los que no había tomado parte. El Libro $X X$ confirma que «no es la forma literaria lo que le interesa a Oviedo, sino el jugoso contenido de noticias y secretos ${ }^{73}$. Esto no significa que Oviedo se abstuviera de exponer sus preferencias por una $\mathrm{u}$ otra fuente, con sus razonamientos: no había tres verdades, sino sólo una, y ésta debía reconstruirla el lector con ayuda del propio cronista. Esta minuciosa estrategia, inspirada en Tucídides, quien había escrito su Historia tras entrevistar a los supervivientes de las guerras, minimizaba las incorrecciones derivadas de no haber estado presente en aquellas tierras.

Para el relato de la segunda expedición a las Molucas, Oviedo se basa para la primera parte del viaje en la relación que le dejó el fraile Juan de Areyzaga (capítulos V-XIV), continuando con la aventura del patache hasta la costa pacífica de Nueva España. Desde la travesía del Pacífico en adelante, Oviedo toma como referencia los testimonios de Andrés de Urdaneta y Martín de Islares, a quienes entrevistó mientras era capitán de la fortaleza de Santo Domingo. En cualquier caso, el riguroso método compilatorio elegido por Oviedo convirtió al Libro $X X$ en un texto estructuralmente desigual y redundante en algunas partes, pero coherente con las irrenunciables premisas de veracidad que se había impuesto, con lo que el sujeto narrativo desaparece parcialmente para dejar espacio a las voces testimoniales.

La segunda consecuencia de tener que narrar unos hechos de oídas es la constante intervención del narrador para confirmar, desautorizar y comentar las más diversas informaciones fundamentando sus juicios en las razones más dispares: la personalidad del autor, su nacionalidad, su experiencia o su confirmación en alguna fuente clásica. El método de pesquisas aparece por primera vez al comentar las diversas versiones de la muerte de Magallanes: tras la presentar la versión de Maximiliano Transilvano, el cronista inserta la explicación de Pigafetta, y a continuación aparece el narrador para tomar parte en la disensión:

Así que, esto es lo que en este caso cuenta aquel caballero Vicentino; pero en lo de suso yo he seguido a relación que Johan Sebastian del Cano me dio, que es aquel capitán que volvió a España con la nao Victoria (como adelante se dirá), y

sus días en la ciudad de Quito hacia 1548. Véase Bienes del difunto Hernando de Bustamante, Archivo General de Indias, Sevilla, Audiencia de Panamá, 235, libro 8, folio 206vbis-207r.

73 Gerbi, 1992: 279. 
casi la misma relación que yo sigo escribió el bien enseñado secretario de César, llamado Maximiliano Transilvano, al cardenal Salcenburgense; y por tanto acabaré la relación del dicho Juan Sebastián del Cano, y después de ella diré algunos pasos notables que dice el Pigafetta, que me parece que no se deben dejar en silencio ${ }^{74}$.

Al hablar de las perlas gigantes del rey de Borneo, Oviedo afirma que «yo quise con diligencia informarme de esto, y lo pregunté a Juan Sebastián del Cano y a Fernando de Bustamante: y me dijeron que era burla y que nunca tal corona ni perlas vieron ${ }^{75}$. Oviedo no da demasiado crédito a la relación de Pigafetta y opta por parafrasearla introduciéndola en cada párrafo con un «Dice». Así, Pigafetta afirma que Magallanes sabía de la existencia del estrecho por una carta náutica obra de Martín de Bohemia, pero Oviedo le contradice tajantemente: «hasta ahora no hay memoria entre bohemios ni entre cristianos que en Bohemia haya nacido cosmógrafo de tanto crédito ${ }^{76}$. Cuando Pigafetta habla de gallinas que ponen huevos tan grandes como de ánsares en Massawa cuyos polluelos nacen al enterrase bajo tierra, Oviedo replica:

... pero pues no dice que vio la experiencia de este sepultar los huevos y nacer como dice, tampoco lo apruebo ni lo niego, pues a Dios es todo posible y de la natura no podemos juzgarla en tales casos por conjeturas ni hablas de los que no lo hubieren experimentado ${ }^{77}$.

Nuestro cronista deja en suspenso la veracidad de esta información, pero dadas las maravillas naturales vistas por él en el Nuevo Mundo, pudiera ser, si se confirmara, una prueba más de la inconmensurabilidad de la creación divina: ésa era, en efecto, una de las intenciones de su Sumario (1526). En cualquier caso, Oviedo duda de varias de las informaciones contenidas en la relación de Pigafetta, a pesar de que su autor fue testigo de todo aquello que narra. Oviedo se destaca entre sus contemporáneos «por una actitud de reser-

${ }^{74}$ Fernández de Oviedo, 1852, vol. II: 15. A pesar de lo que aquí afirma Oviedo, este primer capítulo se basa en Maximiliano Transilvano — quien había entrevistado a Elcano-: algunas partes, como el parlamento de Magallanes para dar ánimos a la tripulación durante la dura travesía del estrecho, o la descripción de las costumbres de los habitantes de Borneo, están claramente extraídas del De Moluccis Insulis. Oviedo trataba de ocultar que, en definitiva, estaba narrando la circunnavegación a partir de una narración de oídas.

75 Ibidem: 18. Estas líneas confirman, en efecto, que este capítulo se basaba en la relación de Transilvano. Juan Sebastián Elcano no puede refutarse a sí mismo.

76 Ibidem: 22. Sin embargo, esta persona si existió: Martín Behaim (1459-1507) llegó a participar en algunas expediciones portuguesas a África y dejó el primer globo terráqueo que se conserva, el Erdapfel (1492).

77 Ibidem: 24. 
va rayana en la incredulidad ${ }^{78}$. El capítulo tercero transcribe fragmentos enteros de la relación, indicando el capítulo concreto de la obra original y desechando todo aquello que considera fabuloso - como el conocido ejemplo de las hojas andantes - o inexacto en lo que se refiere a medidas geográficas. Quizás lo más interesante es que el procedimiento textual de cita y valoración de cada una de sus fuentes ${ }^{79}$ aparece explicado al final del capítulo:

Yo he resumido de esta relación lo que me ha parecido que conviene con la historia y a nuestro propósito de la Especiería, dejando otras muchas cosas por incompetentes para aquí y desechando fábulas y conjeturas, sino memorando otras cosas notables, y otras que concuerdan con el primer capítulo y con otros hombres de crédito que se hallaron en este viaje ${ }^{80}$.

Oviedo es un historiador metarreflexivo, pero lo más significativo es que sacrifica la narración unitaria y coherente para ofrecer a cambio al lector las actas de sus pesquisas en torno a tres versiones del viaje de Magallanes-Elcano: su obsesión por presentar la versión más cercana a la verdad de lo ocurrido acaba por atomizar la historia. Así mismo, aprovecha su experiencia personal en cada oportunidad para dar mayor validez al texto: de Juan Serrano, que reemplazó a Magallanes tras su muerte, afirma que lo conoció y que valía para piloto, pero no para capitán, con lo que así quedaba explicado el error que causó su muerte y la de muchos de sus compañeros en una emboscada $^{81}$. Da noticia del pájaro sagrado de los habitantes de las Molucas, pues Urdaneta, nos informa, le dio un ejemplar ${ }^{82}$. En el relato del padre Juan de Areyzaga confía plenamente, pues habló con él, pero el testimonio de su experiencia en Nueva España lo desecha inmediatamente por tener noticia de otros que conocen la tierra mucho mejor que él, «que pasó poco tiempo» ${ }^{83}$. Oviedo sospecha que el animal descrito por este clérigo en Patagonia «son los mismos animales que en la provincia de Cueva llaman beorí, donde yo los he visto y comido en la Tierra Firme» ${ }^{84}$. En todos estos ejemplos vemos que existe por parte de Oviedo una enfática puesta en escena: como autor que reclama atención para sí, y como historiador que se apropia del discurso de la verdad, una verdad que trata de obtener a través del procedimiento judi-

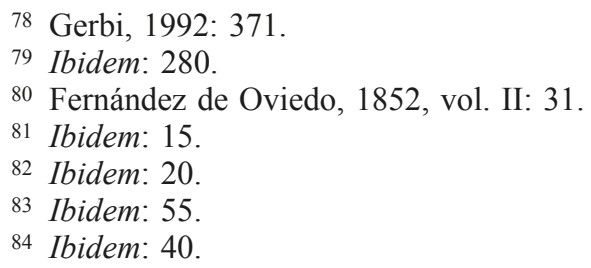


cial ${ }^{85}$. Oviedo refuerza más que ningún otro cronista la relación entre el testimonio histórico y la autoridad historiográfica: es, además, el único de los cronistas contemporáneos a los hechos que relata que toma parte en algunas de las expediciones americanas. La colación de relaciones de testigos presenciales y las fuentes clásicas, por este orden, serán las otras apoyaturas de su autoridad $^{86}$. El Libro XX será, por defecto, ejemplo perfecto de esta voluntad de apropiación de la verdad a través de fuentes secundarias, y de ahí, precisamente, su problemática construcción que no aparece en otros libros de su magna obra: sacrifica la armonía la narrativa a la verdad.

Magallanes ocupa un lugar preferente dentro del libro: su capacidad de liderazgo, su valiente iniciativa, su ferviente catolicismo y su papel como sostenedor de la empresa hasta su trágica muerte son ensalzadas por Oviedo $\mathrm{y}$ «responden a una imagen cortesana y caballeresca del siglo $\mathrm{XVI} \mathrm{I}^{87}{ }^{87}$ : son, dentro de su relato legitimador, personajes literarios necesarios. La crueldad de que hace gala Magallanes ante los amotinados en el estrecho es minimizada y sólo interrumpe la relación de Transilvano para mostrar la versión de Pigafetta de su muerte, en la que su figura aparece más realzada. Elcano, de cuya participación en el motín no se hace mención, es el esforzado capitán capaz de superar todas las adversidades por servir a su patria y a su rey. El vizcaíno es justamente recompensado con la entrega de un escudo de armas, pero Oviedo, que entiende su oficio como un servicio a la justicia y a la posteridad, no tiene inconveniente en dar todo el mérito de la empresa al portugués: «no obstante que por las relaciones de suso parece que Fernando de Magallanes no llegó a las islas de los Malucos y la Especiería, este loor a sólo Magallanes se le debe, y a él se atribuye este gran viaje y descubrimiento» ${ }^{88}$. Este ideal de justicia histórica era una responsabilidad que el propio cronista asumía como parte integrante de su labor y del discurso moralizador y didáctico que, a fin de cuentas, constituía la razón de ser su obra. De ahí que introduzca un excurso para criticar a los cosmógrafos que en sus cartas cambian los nombres de los accidentes geográficos, dejando en injusto olvido a sus descubridores:

La malicia de los que después siguen estos descubrimientos, para apropiarse a sí más de lo que hacen, muda y trueca los nombres para oscurecer la fama y loor de los que les deben preceder. Testigo soy de vista de algunas malicias de éstas que he visto usar a algunos gobernadores y capitanes en la Tierra Firme; pero si

\footnotetext{
85 Carrillo, 2003: 11.

86 Adorno, 1992.

87 Coello de la Rosa, 2012: 92.

88 Fernández de Oviedo, 1852, vol. II: 34.
} 
yo tengo vida, para acabar estas historias, o a lo menos en lo que yo escribiere, será guardado su lugar a cada uno ${ }^{89}$.

El recurso a los mitos y leyendas del pasado le servirá, a lo largo de la Historia, para afirmar su identidad letrada, de humanista culto al servicio del rey: una convención retórica que le incluía dentro de una tradición historiográfica. Representando el Nuevo Mundo como réplica y cambio de los mitos del Viejo Mundo, Oviedo establecía una continuidad entre ellos en la que América acaba por reemplazar a su modelo en términos de superioridad ${ }^{90}$ :

Fue el camino que esta nao hizo el mayor y más nueva cosa que desde Dios crió el primer hombre y compuso el mundo hasta nuestro tiempo se ha visto, y no se ha oído ni escrito cosa más de notar en todas las navegaciones después de aquella del Patriarca Noé91.

La hazaña de la tripulación culminaba una serie de navegaciones históricas. Pero, además, en el caso del Libro $X X$, la referencia clásica —en este caso, Plinio - le servirá para dar credibilidad a una información fabulosa: la existencia de gigantes patagones. Oviedo, tras describir su portento físico y otras cualidades - «tan veloces en el correr como muy ligeros caballos o más» ${ }^{92}$ - previene al lector de su sorpresa, haciéndole saber que Plinio había escrito acerca de otros hombres aún más asombrosos, como los etíopes o los trogloditas. Esta concesión a lo fabuloso es especialmente significativa sobre todo si tenemos en cuenta que nuestro cronista no era dado a incluir seres fantásticos dentro de su obra aun cuando la existencia de éstos pudiera de algún modo apoyarse en referencias a textos antiguos. Oviedo, además, profesaba un profundo desprecio por las obras de imaginación: "La investigación y la aprehensión de la verdad tenían para él un valor moral mucho más alto que la creación artística» ${ }^{93}$. El encuentro con los patagones, a quienes el clérigo Juan de Areyzaga «no llegaba a sus miembros vergonzosos en altor ${ }^{94}$, servía para reforzar el heroísmo de los arrojados españoles, amplificar su hazaña como pueblo escogido por Dios, así como disuadir a los competidores ${ }^{95}$.

\footnotetext{
89 Ibidem: 48.

90 Myers, 1991.

91 Fernández de Oviedo, 1852, II: 34.

92 Ibidem: 57.

93 Gerbi, 1992: 269.

94 Fernández de Oviedo, 1852: II, 43.

95 Coello de la Rosa, 2012: 113.
} 
Oviedo adereza el texto insertando pequeñas historias curiosas, como la aventura del patache San Juan hasta el encuentro del clérigo con el gobernador de Tehuantepec (cap. XII), el relato detallado de las relaciones con los patagones, o la anécdota de un indio de Machian, en las Molucas, que, viendo que iba a ser apresado por los portugueses, prefirió matar a su mujer y a sus hijos para que no cayeran esclavos y morir en la pelea ${ }^{96}$. La escena cumplía con los requisitos de didactismo y moralidad que Oviedo buscaba como historiador: exponer un modelo de conducta digno de ser emulado, sobre todo por parte de los españoles. Sin embargo, este didactismo a veces es fruto del grandísimo placer que Oviedo parecía sentir al acumular novedades referentes a los modos de vida de los indígenas, los frutos, las plantas o los animales. Este afán compilatorio es el que hace que nuestro autor sea «más grande como naturalista que como historiador, como etnógrafo y geógrafo que como cronista de la empresa conquistadora» ${ }^{97}$, aunque en esta precisa ocasión sus fuentes e informantes no den lugar a que luzca su hambre de conocimiento como en otras secciones de su Historia. No hay información nueva que pueda añadir respecto a los nativos de Filipinas — «gente belicosa y sagaz y muy falsos» ${ }^{98}$ - , Borneo o las islas de los Ladrones: todo está ya en el Transilvano, Pigafetta o Urdaneta. Los capítulos XXXIV y XXXV son un recuento de la gente que habita en Molucas, Célebes, Banda, Java y Sumatra, con especial atención a los frutos, el oro y las especias que producen: en estos capítulos finales el cronista despliega la curiosidad que es tan visible en otras partes de su Historia. Este didactismo le llevó a incluir ilustraciones con las que paliar la expresión de nuevas realidades que, en ocasiones, las palabras no podían expresar con tanta exactitud ${ }^{99}$. Cabe suponer que si no incidió más extensamente en esta ocasión fue debido a la escasez de fuentes.

Fernández de Oviedo se propuso la escritura de una historia total, de carácter enciclopédico, que ensalzara a los grandes hombres de la empresa conquistadora, que diera cuenta de las acciones llevadas a cabo en ultramar con el mayor rigor y exhaustividad, una obra tan abarcadora y ambiciosa que se convirtiera en referencia para los lectores contemporáneos, pero con clara vocación de permanencia en la posteridad. El Libro XX, desigual, heterogéneo,

96 Fernández de Oviedo, 1852, vol. II: 84. Esta misma anécdota aparece en la relación de Urdaneta.

97 Gerbi, 2012: 294.

98 Fernández de Oviedo, 1852, vol. II: 64.

99 Turner, 1985: 1-46. Una extensa colección de dibujos originales, extraídas de los manuscritos, se halla en el apéndice de Myers, 2007: 188-270. 
repetitivo a veces y falto de informaciones en otras ocasiones, renuncia a ofrecer una versión sintética y cohesionada de la primera circunnavegación en aras de su búsqueda de la verdad, mientras que la narración de la expedición liderada por Loaysa, convertida circunstancialmente en un animado relato de aventuras en el marco de las Islas de las Especias, contiene, a pesar de las digresiones e intereses del sagaz compilador, todas las virtudes y defectos de la relación original de Urdaneta. En Oviedo - como en Anglería o en Gómara - , la imagen que ofrece en conjunto del sudeste asiático todavía en el tercer cuarto del siglo XVI es una imagen marcada por la precariedad, tan borrosa como los tímidos mapamundis que por entonces trataban de ubicar y dar forma a ese universo «archipielágico» cuya lejanía había acabado por preterirlo en el concurso de los conocimientos humanos y geográficos. $\mathrm{Al}$ fin y al cabo, las crónicas se debían por encima de todo a una misión de servicio al rey y la religión, y durante estos primeros cincuenta años de contactos esporádicos, el sudeste asiático continuó siendo una tierra relativamente enigmática en donde los españoles lucían sus lustres. Sólo hacia 1565, con la entrada de Legazpi en Cebú, Filipinas y, por extensión, Asia Oriental, encontrarán verdaderamente su lugar, su función y su carácter dentro del ámbito de lo hispánico: devendrán una nueva realidad dispuesta para ser explotada literariamente ${ }^{100}$.

\section{BIBLIOGRAFÍA}

Adorno, Rolena, "The Discursive Encounter of Spain and America: The Authority of the Eyewitness Testimony in the Writing of History", The William and Mary Quaterly, XLIX/2 (Williamsburg, 1992): 210-228.

Argensola, Bartolomé Leonardo de, Conquista de las Islas Molucas, prólogo de Gloria Cano, Madrid, Miraguano Ediciones, 2009.

Brennan, Michael G., "The Texts of Peter Martyr's De orbe novo decades (15041628): A Response to Andrew Hadfield", Connotations, 6/2 (Münster/New York, 1996-1997): 227-245.

Carrillo, Jesús, "La teatralización de la verdad en Fernández de Oviedo", Iberoromania, 58/2 (Heidelberg, 2003): 9-24.

Castany Prado, Bernat, "Francisco de Gómara y Jean de Léry: escepticismo moderado y escepticismo radical en las crónicas de Indias", Guillermo Serés y Mercedes Serna (eds.), Los límites del océano: estudios filológicos de crónica y

100 Ruíz Pérez, 1993: 45. 
épica en el Nuevo Mundo, Bellaterra, Centro para la Edición de los Clásicos Españoles, 2009: 9-24.

Cazés, Dann, "La metarreflexión histórica en la obra de López de Gómara", Karl Kohut (ed.), Narración y reflexión. Las crónicas de Indias y la teoría historiográfica, México D.F., El Colegio de México, 2007: 133-162.

Chirino, Pedro, Historia de la provincia de Filipines de la Companyia de Jesus: 1581-1606, edición de Jaume Gorriz, Barcelona, Portic, 2000.

Coello de la Rosa, Alexandre, Historia y ficción. La escritura de la 'Historia General de las Indias' de Gonzalo Fernández de Oviedo y Valdés (1578-1557), Valencia, Universitat de València, 2012.

Cro, Stelio, "La «Princpes» y la cuestión del plagio del De Orbe Novo", Cuadernos para la investigación de la literatura hispánica, 28 (Madrid, 2003): 15-240.

Cuesta Domingo, Mariano, "Los cronistas oficiales de Indias. De López de Velasco a Céspedes del Castillo", Revista Complutense de Historia de América, 33 (Madrid, 2007): 115-150.

Fernández de Oviedo y Valdés, Gonzalo, Historia General y Natural de las Indias, Islas y Tierra Firme del Mar Océano, editada por Amador de los Ríos, Madrid, Imprenta de la Real Academia de la Historia, 1852, 4 vols.

Gerbi, Antonello, La Naturaleza de las Indias Nuevas, México, Fondo de Cultura Económica, 1992.

Herrera, Antonio de, Historia General de los hechos de los castellanos en las islas y Tierra firme del mar océano, edición y estudio de Mariano Cuesta Domingo, Madrid, Universidad Complutense, 1991, 4 vols.

Kohut, Karl, "Las primeras crónicas de Indias y la teoría historiográfica", Colonial Latin American Review, 18/2 (New York, 2009): 153-187.

López de Gómara, Francisco, Historia General de las Indias y Vida de Hernán Cortés, Caracas, Biblioteca Ayacucho, 1979.

Mampel González, Elena y Escandell Tur, Neus (eds.), Lope de Aguirre. Crónicas 1559-1561, Barcelona, Ediciones 7 1/2/Ediciones Universidad de Barcelona, 1981.

Mártir de Anglería, Pedro, Décadas del Mundo Nuevo, editado por Ramón Alba, Madrid, Ediciones Polifemo, 1990.

Mora, Carmen de, "Dimensiones de la prosa barroca en Hispanoamérica", Anales de Literatura Hispanoamericana, 28 (Madrid, 1999): 283-295.

Myers, Kathleen A., "Imitation, authority, and revision in Fernández de Oviedo's Historia General y Natural de las Indias", Romance Languages Annual, 3 (West Lafayette, 1991): 523-530.

Myers Kathleen A., Fernández de Oviedo's Chronicle of America. A New History for New World, Austin, Texas University Press, 2007. 
Pérez de Tudela Bueso, Juan, "Vida y escritos de Gonzalo Fernández de Oviedo", Gonzalo Fernández de Oviedo, Historia General y Natural de las Indias, Madrid, Biblioteca de Autores Españoles, 1959, vol. 1.

Ramos Pérez, Demetrio, "Fernández de Oviedo y el «Enigma» de la Edición de 1547 de su Historia General", Boletín Americanista, 19-27 (Barcelona, 1965): 5-19.

Rey, Agapito, "Book XX of Oviedo's Historia General y Natural de las Indias", The Romanic Review, XVIII (New York, 1927): 52-57.

Riber Campins, Lorenzo, El humanista Pedro Mártir de Anglería, Barcelona, Editorial Barna, 1964.

Roa-de-la-Carrera, Cristian A., Histories of Infamy: Francisco López de Gómara and the Ethics of Spanish Imperialism, Boulder, University of Colorado, 2005.

Ruíz Pérez, Pedro, "Introducción: entre la historia y la literatura", Fernán Pérez de Oliva, Historia de la Invención de las Yndias. Historia de la conquista de la Nueva España, Córdoba, Universidad de Córdoba, 1993: 7-128.

Salas, Alberto Mario, Tres cronistas de Indias, Buenos Aires, Losada, 1960.

Serna, Mercedes, "José de Acosta y las cosmografías fabulosas de la Antigüedad", Guillermo Serés y Mercedes Serna (eds.), Los Límites del Océano. Estudios Filológicos de Crónica y Épica en el Nuevo Mundo, Bellaterra, CECE/Universidad Autónoma de Barcelona, 2009: 261-275.

Serna, Mercedes, "Censura e Inquisición en las Crónicas de Indias. De sus adversidades e infortunios", Bernat Castany Prado (ed.), Tierras prometidas: de la colonia a la independencia, Bellaterra, Centro para la Edición de los Clásicos Españoles, 2011: 347-360.

Soler, Isabel, El sueño del rey. Viajes y mesianismo en el Renacimiento peninsular, Barcelona, Acantilado, 2015.

Turner, Daymond, “The Aborted First Printing of the Second Part of Oviedo's General and Natural History of the Indies", Huntington Library Quaterly, 46/2 (Philadelphia, 1983): 105-125.

Turner, Daymond, "Forgotten Treasure from the Indies: The Illustrations and Drawings of Fernández de Oviedo", Huntington Library Quaterly, 48/1 (Philadelphia, 1985): $1-46$.

Valcárcel Martínez, Simón, "Una aproximación a Francisco López de Gómara”, Caravelle, 53 (Toulouse, 1989): 7-24.

White, Hayden, El contenido de la forma, Barcelona, Paidós, 1992.

Fecha de recepción: 13 de febrero de 2017.

Fecha de aceptación: 17 de julio de 2017. 


\section{The Philippines in the early historiography of the Indies}

The earliest references to the Philippines and South East Asia have traditionally been left on the sidelines in the historiography of the Indies. In their chronicles, Peter Martyr di Anghiera, López de Gómara and Fernández de Oviedo all provided an official version of the first circumnavigation of the globe and the Spanish presence in the Philippines and Moluccas Islands. The present work explores the way these authors approached those crucial historical events, in which they did not take part, in order to elucidate their narrative strategies, their attitude towards classical authors and their differences when compared to the direct testimonies of witnesses of the narrated events.

Key words: Philippines; Moluccas Islands; sixteenth-century historiography; Chronicles of the Indies; Colonial Literature. 